\title{
Risk measurement of international oil and gas projects based on the Value at Risk method
}

\author{
Cheng Cheng ${ }^{1} \cdot$ Zhen Wang ${ }^{2} \cdot$ Ming-Ming Liu $^{2} \cdot$ Xiao-Hang Ren ${ }^{3}$
}

Received: 20 January 2018/Published online: 23 November 2018

(C) The Author(s) 2018

\begin{abstract}
International oil and gas projects feature high capital-intensity, high risks and contract diversity. Therefore, in order to help decision makers make more reasonable decisions under uncertainty, it is necessary to measure the risks of international oil and gas projects. For this purpose, this paper constructs a probabilistic model that is based on the traditional economic evaluation model, and introduces value at risk $(\mathrm{VaR})$ which is a valuable risk measure tool in finance, and applies VaR to measure the risks of royalty contracts, production share contracts and service contracts of an international oil and gas project. Besides, this paper compares the influences of different risk factors on the net present value $(N P V)$ of the project by using the simulation results. The results indicate: (1) risks have great impacts on the project's $N P V$, therefore, if risks are overlooked, the decision may be wrong. (2) A simulation method is applied to simulate the stochastic distribution of risk factors in the probabilistic model. Therefore, the probability is related to the project's $N P V$, overcoming the inherent limitation of the traditional economic evaluation method. (3) VaR is a straightforward risk measure tool, and can be applied to evaluate the risks of international oil and gas projects. It is helpful for decision making.
\end{abstract}

Keywords Risk measurement - Value at risk - International oil and gas projects · Fiscal terms · Probabilistic model

\section{Introduction}

High risk is one of the most distinguishing features of international oil and gas (OG) projects. Suslick and Schiozer (2004) and Welkenhuysen et al. (2017) suggested that geological risk, economic risk and engineering risk should all be considered because they influence the exploration and development of OG projects. As both geological risk and engineering risk affect the uncertainty of volumes and production plans of oil and gas projects, we propose to use resource risks to represent geological risk

Edited by Xiu-Qin Zhu

Zhen Wang

wangzhen@cup.edu.cn

1 School of Management Science and Engineering, Shanxi University of Finance and Economics,

Taiyuan 030006, Shanxi, China

2 Academy of Chinese Energy Strategy, China University of Petroleum-Beijing, Beijing 102249, China

3 School of Mathematical Sciences, University of Southampton, Southampton SO17 1BJ, UK and engineering risk. Besides, Liu et al. (2012) and Zhu et al. (2015) mentioned that policy risk, especially fiscal risk, has important impacts on international OG projects. Moreover, Zhang et al. (2012) and Wang and Zhang (2012) proposed that resource risks, economic risks and policy risks should be considered in the evaluation process of international OG projects. In summary, there are three types of risks for an operating international OG project: (1) resource risks. They mainly influence the production of the projects, and include geological structure, recovery ratio, resource quality, production planning and so on. They can be classified into geological risk, resource acquisition risk, and engineering risk. The geological risk is related to underground structures; resource acquisition risk is related to OG quality and difficulties of exploitation, both of them have impacts on the volumes of OG resources. Meanwhile, engineering risk is related to engineering technology, production planning and other factors; they have impacts on the volumes of produced OG. (2) Economic risks. They affect the costs and prices of the product, and contain production costs, operating costs, OG prices, exchange rates and so on. They influence the net revenues of $\mathrm{OG}$ projects. (3) Policy risks. They impact the projects from 
different aspects-policy risks may influence the project revenues or the project costs, and may even affect the demand and supply of the product. They consist of fiscal policies, nationalization policies and so forth; among which fiscal policies affect the revenue distribution of OG projects between resource countries and OG companies, and nationalization policies affect the ownership of OG projects. These risk factors exist in the whole project life cycle and always affect the project values.

Apart from high risk, international OG projects have other features: (1) international OG projects are featured by high investment and high returns. Investment is enormous for international $\mathrm{OG}$ projects, frequently more than 10 million US dollars. Meanwhile, the potential returns are also substantial for international OG projects, usually as high as 100 million dollars. Besides, there are over a dozen factors that have impacts on the project returns, among which several are risk factors. Therefore, the impacts of risk factors on project values is relatively significant for international OG projects, which make it urgent to measure the risks of international OG projects. (2) The revenue distribution of international OG projects depends on contract types. The revenue distribution is different for royalty contracts, production share contracts, and service contracts. Therefore, contract diversity complicates the risk measurement of international OG projects. What is more, it makes this study more valuable. In summary, it is essential to study the impacts of risk factors on the values of international OG projects, aiming to help decision makers make more reasonable decisions given the uncertainties.

The widely used methods for quantitative risk analysis on project values include: (1) the exhaustion method, which lists all possible values of risk factors (SQW 2010). This method contains all the possible values. However, the corresponding possibilities are overlooked. (2) The most likely value method, which uses the most likely values of risk factors (Dalton et al. 2012). This method is affected by the subjective probabilities. Besides, even though the most likely values of risk factors are applied, the probability that all the most likely values appear simultaneously is much smaller (Hertz 1964). (3) The scenario analysis method, which sets several scenarios, and estimates and compares the results in different scenarios. However, the probability of different scenarios cannot be obtained. (4) The minimum expected return rate method, which aims to estimate the minimum expected return rate of a project under given parameters (Weijermars et al. 2017; Welkenhuysen et al. 2017). Although this method can be used to estimate the benchmark, the corresponding confidence level cannot be obtained.

In summary, the above four methods cannot provide the confidence levels (or probabilities) of different results. For the investors, they hope to fully recognize the impacts of all risk factors on the project values. If they overlook the impacts of risk factors, they may bias the project values, and lower the decision's reliability (Mohamed and McCowan 2001). Therefore, the confidence levels are very important for investors because if investors are not sure whether they can obtain enough profits, they may choose to give up. Therefore, it is necessary to apply an appropriate method for risk measurement of international OG projects, which can link the probabilities with all the possible results. A probabilistic model, which simulates the risk factors to obtain all possible results, is a suitable method because it can comprehensively evaluate the impacts of risk factors on the project values, and it can also link the probabilities with all the possible results ( $\mathrm{Hu}$ and Shen 2001; Yan et al. 1999). Therefore, a probabilistic model is applied in this paper to measure the risks of international OG projects.

The application of the probabilistic model is divided into three areas_-value estimation, resource evaluation and policy appraisal.

(1) Studies of the value estimation concentrate on three aspects: (a) optimization research. Goel and Grossmann (2004) applied a simulation method in the investment and production optimization process of an offshore gas field which faces reserve uncertainty. Lin et al. (2013) used a probabilistic model to optimize the production scheme of a deep-water OG project in West Africa which is under reserve uncertainty, equipment uncertainty, and market uncertainty. (b) Value estimation. van der Poel and Jansen (2004) applied a probabilistic model to study the impacts of intelligent well completion on the OG project values. Khadem et al. (2017) applied the probabilistic model to conduct quantitative risk management of an oil and gas project in Oman. Welkenhuysen et al. (2017) applied a probabilistic model to evaluate a $\mathrm{CO}_{2}$-EOR project which faces oil price uncertainty, recovery rate uncertainty, $\mathrm{CO}_{2}$ price uncertainty, and uncertainty of the mean value of the production curve. Weijermars et al. (2017) used a probabilistic model to compare the return rate of shale blocks in the Eagle Ford in the USA and Mexico. (c) Cost analysis. Méjean and Hope (2008, 2013) applied the probabilistic model to estimate the costs of Canadian bitumen and Canadian synthetic crude oil.

(2) Studies of the resource evaluation mainly estimate the key indicators of an OG project, such as original oil/gas in place, technically recoverable resources and recovery factor. Dong et al. (2013) and Richardson and Yu (2018) applied a probabilistic model to estimate the resource indicators of shale gas 
reservoirs. Osterloh et al. (2013) applied a probabilistic model to estimate the resource indicators of a heavy oil reservoir.

(3) Studies of the policy evaluation mainly evaluate the policies which influence the net present value (NPV) of OG projects. Liu et al. (2012) applied a probabilistic model to thoroughly study the impacts of key fiscal terms of a production share contract on the values of OG projects under oil price uncertainty. Wang et al. (2012) applied a probabilistic model to analyze the impacts of the key terms in a royalty contract on the NPV of an international OG projects. Besides, other scholars applied a probabilistic model to production prediction (such as Rivera et al. (2007)), to well construction (such as McIntosh (2004) and Adams et al. (2010)) and so on.

In summary, although the probabilistic model is widely applied in OG studies, most of the previous studies focus on resources indicators, especially the papers published by SPE, and aim to estimate the technically recoverable resources. Other studies applied the probabilistic model to investigate the impacts of risk factors on the $N P V$ of the OG projects. However, they lack a standard research framework. Liu et al. (2012) and Wang et al. (2012) conducted similar studies, however, they confined their studies to a certain fiscal system, and they mainly studied the impacts of oil uncertainty. In order to propose a research framework and to comprehensively measure the risks of international OG projects, this paper chooses risk factors from resource uncertainties, economic uncertainties, and policy uncertainties, then simulates the risk factors based on a traditional $N P V$ model and compares the impacts of different risk factors on the $N P V$ based on the proposed research framework.

It is necessary and meaningful to quantitatively estimate the risks of international OG projects and to study the impacts of different risk factors. Therefore, in order to address these issues, this paper proposes a research framework (the probabilistic model), in which a Monte Carlo Simulation method and VaR are applied. The probabilistic model provides the distribution of $N P V$ and $\mathrm{VaR}$, therefore it is helpful for decision makers to acknowledge the risks of international OG projects and make decisions based on this information. The contribution of this study is that it considers the features of the appraisal of international $\mathrm{OG}$ projects, and introduces $\mathrm{VaR}$ to the research framework of the probabilistic model, which provides a new method for the risk measurement of international OG projects.

The remaining paper is organized as follows: The framework of the probabilistic model and the concept of $\mathrm{VaR}$ are described in Sect. 2. The probabilistic model is set up in Sect. 3. Section 4 presents the parameters and results of different fiscal systems. Section 5 is the conclusion of this paper.

\section{Probabilistic model and VaR}

The probabilistic model is based on a traditional economic evaluation model, but it overcomes the inherent limitation of traditional economic evaluation models by simulating stochastic variables. Besides, an NPV frequency histogram can be obtained by using a probabilistic model, and then $\mathrm{VaR}$ can be applied to measure the project risks.

\subsection{Probabilistic model}

There are many factors which influence the values of international OG projects, such as resource volume, production curve, investment, operation expenditure, product prices, and taxes. These factors can be divided into two categories, namely the fixed variables and stochastic variables. Fixed variables refer to the certain factors, whose values do not change in the future. Stochastic variables refer to the uncertain factors, whose values are not fixed and may change in the future. Distributions (like the normal distribution, triangle distribution, and uniform distribution) and corresponding parameters (the mean, the standard deviation (Std)) can be used to describe stochastic variables, and historical data or available data can be used to fit the distributions for stochastic variables.

Parameters in the traditional NPV model are assumed to be fixed variables. Therefore, the assumptions in the traditional $N P V$ model are rigid, and they cannot reflect the uncertain factors embedded in the projects. However, parameters in the probabilistic models are divided into fixed variables and stochastic variables, and the Monte Carlo Simulation method is applied to simulate the stochastic parameters. The impacts of stochastic variables on the values of international OG projects are studied, therefore the probabilistic model can overcome the inherent defects of the traditional NPV model. The Monte Carlo Simulation method can comprehensively measure and analyze the stochastic characters of risk factors of international OG projects, therefore it is proper to apply the Monte Carlo Simulation method to measure the impacts of uncertain factors (Falconett and Nagasaka 2010; Montes et al. 2011; Welkenhuysen et al. 2017).

In order to analyze the impacts of risk factors on the values of international OG projects, this paper proposes the analytical framework of the probabilistic model, which is shown in Fig. 1. @RISK software from Palisade (USA) is applied to conduct the Monte Carlo Simulation. After 10,000 iterations, the distribution histogram of the $N P V$ is obtained, and the probability density curve is acquired. 


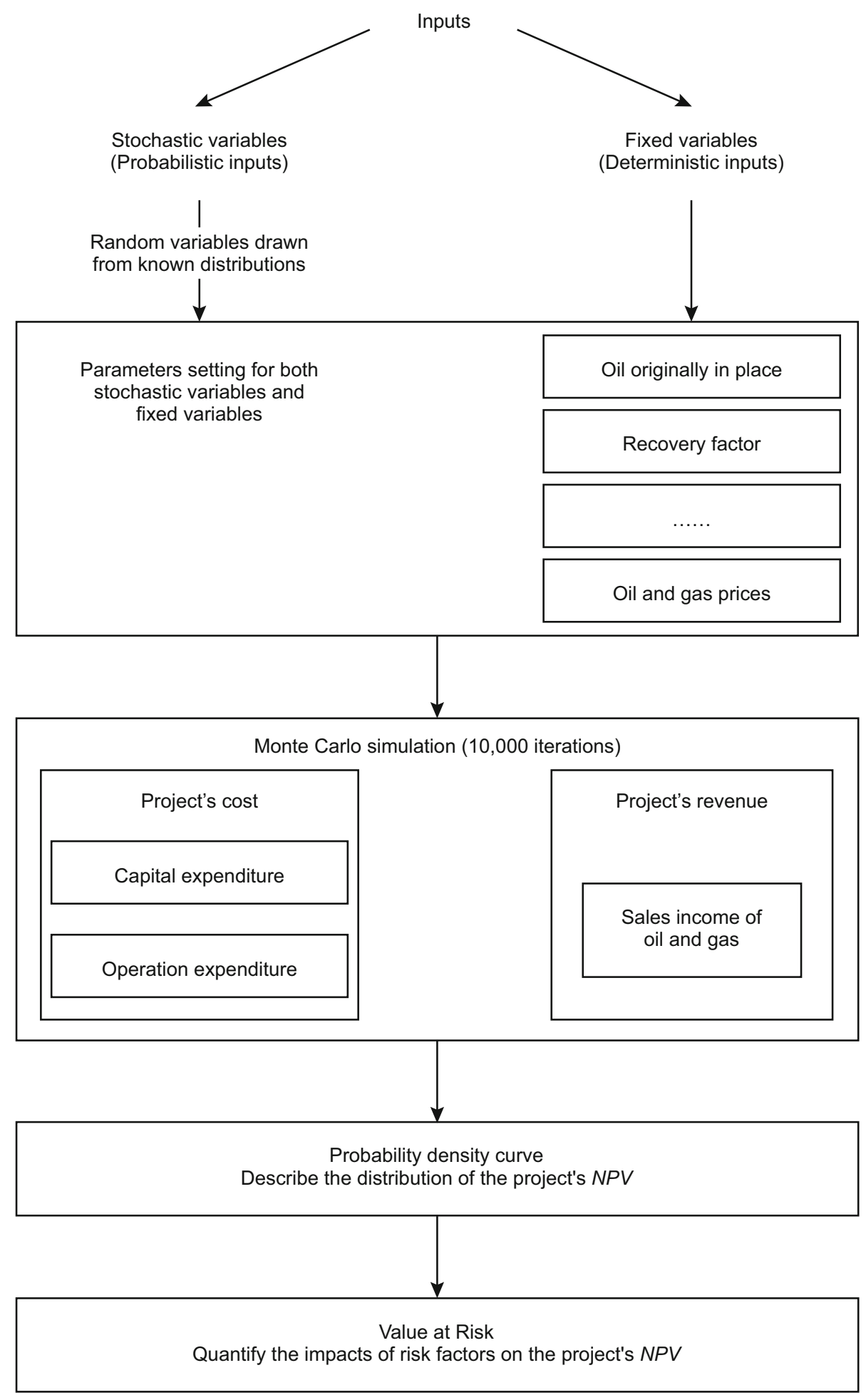

Fig. 1 Framework of the probabilistic method (note: drawn by the authors)

VaR can be applied to measure the probability that the $N P V$ is higher than a certain threshold. Besides, different confidence levels can be selected to measure the thresholds of different risk levels, which can comprehensively measure the risks of international OG projects.

\subsection{Value at Risk}

Value at Risk (VaR) is a tool to measure risks. To be specific, it refers to the largest potential losses of the financial assets or security portfolios held by the investors 
over a certain time interval, given a set probability. It can be calculated by $\operatorname{Prob}(\Delta P \Delta t \leq \mathrm{VaR})=1-\alpha$, where Prob represents the probability that the losses of assets are less than the largest possible losses, $\Delta P \Delta t$ refers to the losses of assets in a set time interval $\Delta t$, and $1-\alpha$ is the confidence level. The definition of VaR is illustrated in Fig. 2a. Decision makers in the financial department are concerned about the potential losses, therefore, they pay more attention to the left tail of the returns curve when they calculate the VaR. In summary, VaR is a straightforward and convenient tool for risk measures, and it is widely used in financial departments because decision makers can quickly acknowledge the impacts of risk factors through several numbers (namely VaRs).

Gass et al. (2011) introduced VaR into value estimation of energy projects. Gass et al. (2011) stated that given a set confidence level $1-\alpha$, the corresponding threshold can be obtained by using the probability density curve of $N P V$. The probability that $N P V$ is less than the threshold is $1-\alpha$, or the probability that $N P V$ is high than the threshold is $\alpha$, namely $\operatorname{Prob}(N P V \leq \mathrm{VaR})=1-\alpha$ or $\operatorname{Prob}(N P V \geq \mathrm{VaR})=\alpha$. VaR of energy projects is illustrated in Fig. 2b. As the decision makers care more about gains than losses when they estimate the project values, decision makers pay more attention to the right tail of the NPV curve.

\section{Probabilistic model}

A probabilistic model is based on the $N P V$ model, while economic evaluation of international OG projects is influenced by many factors, such as production scheme, oil prices, costs, fiscal terms, project revenue, and taxes. Therefore, we set up different models to depict the abovementioned factors to construct the economic evaluation model of international OG projects. Then, we divide the

(a) VaR of finance

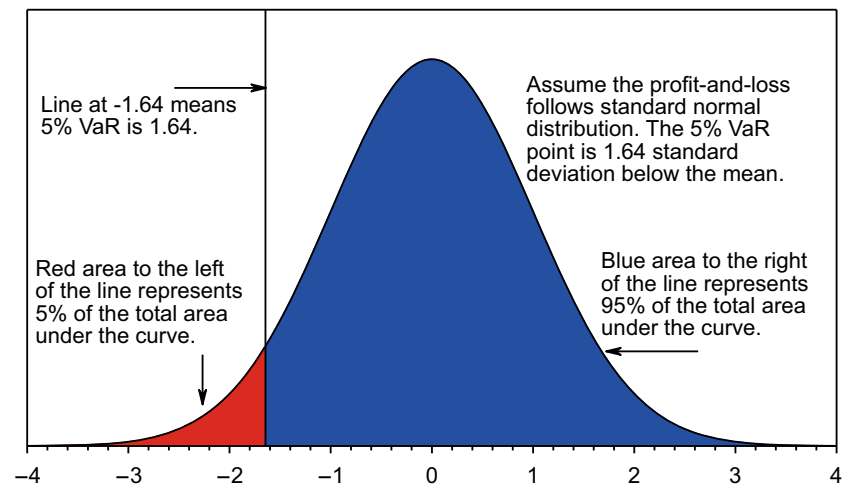

factors into stochastic variables and fixed variables, and we finally employ@RISK to simulate the stochastic variables.

\subsection{Production model}

In general, the production of the OG projects in the initial stage is small, then it starts to increase until it reaches the production plateau. After that, it starts to decrease until the OG field is abandoned. There are different kinds of production curves that are used to depict the production scheme (e.g., Arps 1945; Fetkovich 1980; Höök and Aleklett 2008), among which the lognormal curve is widely used (Welkenhuysen et al. 2017). It is very convenient to apply a lognormal curve to describe the production curve as the shape of the production curve is decided by the mean $\mu$ and the $\operatorname{Std} \sigma$. The function of the lognormal distribution is:

$y=\frac{1}{x \sigma \sqrt{2 \pi}} \mathrm{e}^{-\frac{(\ln x-\mu)^{2}}{2 \sigma^{2}}}$

With reference to Eq. (1), given that the production scheme follows a lognormal distribution, the annual production of an OG project is calculated as:

$\operatorname{Prod}_{t}=O O I P \times R \times \frac{1}{t \sigma \sqrt{2 \pi}} \mathrm{e}^{-\frac{(\ln t-\mu)^{2}}{2 \sigma^{2}}}$

where $\operatorname{Prod}_{t}$ represents the OG production at year $t, O O I P$ is the oil originally in place, $R$ is the recovery factor, $\mu$ is the mean of production curve, and $\sigma$ is the Std of production curve. The highest point of the production curve is the plateau production, and the shape of the production curve changes when $\mu$ and $\sigma$ change.

As shown in Eq. (2), there are 5 factors that have impacts on production scheme. They can be classified into geological factors, resource acquisition factors and engineering factors. OOIP belongs to geological factors, R falls within resource acquisition factors, and $\mu, \sigma$ and project cycle are part of engineering factors. Given that the other

(b) VaR of energy project

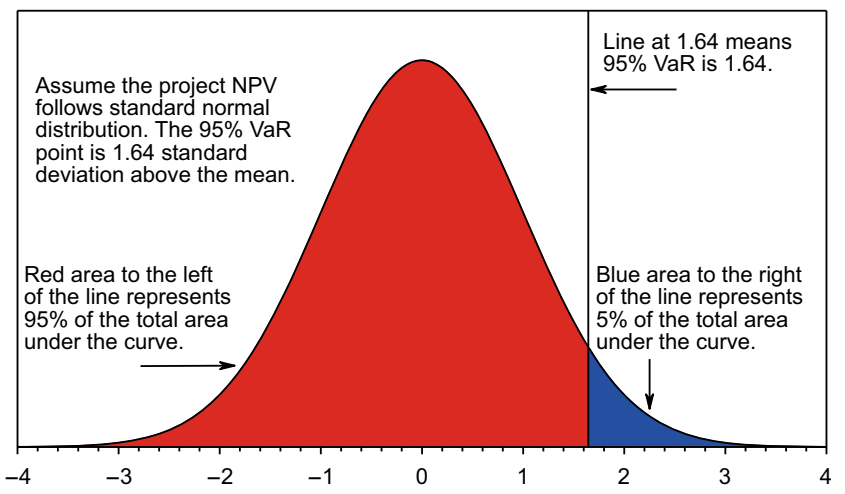

Fig. 2 Value at Risk (note: drawn by the authors) 
factors are fixed, the positive impacts of $O O I P$ on production curve are shown in Fig. 3.

\subsection{Oil price model}

Oil price is affected by many factors, such as fundamentals, future markets and short-term shocks. The oil price is very volatile, and the stochastic process is often used to describe the volatility of oil price. Currently, Geometric Brownian Motion (GBM) and Mean-Reverting Process (MRP) are widely applied to simulate the oil price (Schwartz 1997; Wang and Li 2010; Wang et al. 2010; Zhao and Feng 2009). GBM indicates that the price of underlying assets has a long increasing or decreasing trend, meanwhile, it randomly fluctuates. Therefore, GBM tends to wander far from the starting points. MRP implies that the price of underlying assets tends to wander toward the long equilibrium price while it randomly fluctuates. Compared with GBM, the MRP is more suitable to depict the oil price. Although in short-term oil price might fluctuate randomly in response to the other factors, it is mainly decided by the fundamentals and will draw back toward a normal price in the long term. Therefore, MRP is used in this paper. The simulation process and estimation method of its parameter are shown below.

Assume the MRP of oil price is expressed as:

$\mathrm{d} P=\eta P(m-\ln P) \mathrm{d} t+\sigma P \mathrm{~d} z$

where $\eta$ is the speed of reversion, $P$ is oil price, $m$ is long equilibrium price, $\sigma$ is the variance parameter of oil price and $\mathrm{d} z$ is the increment of a standard Winner process.

Let $X=\ln P$, by applying Ito's lemma in Eq. (3), we obtain:

$$
\begin{aligned}
& \mathrm{d} X=\eta(\alpha-X) \mathrm{d} t+\sigma \mathrm{d} z \\
& \alpha=m-\frac{\sigma^{2}}{2 \eta}
\end{aligned}
$$

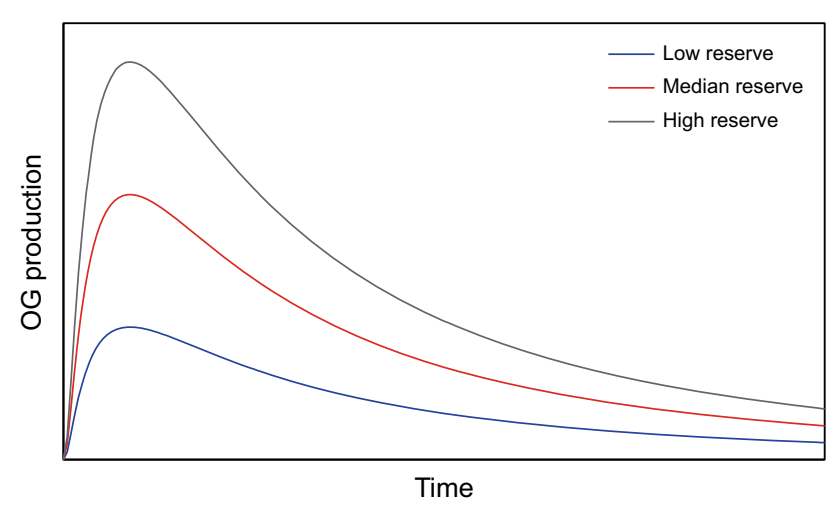

Fig. 3 Impacts of oil originally in place on the production curves (note: drawn by the authors)
Equation (4) implies that the logarithm of oil price $(X)$ obeys the Ornstein-Uhlenbeck process. By using the equivalent martingale measure, the Ornstein-Uhlenbeck process can be expressed as $\mathrm{d} X=\eta\left(\alpha^{*}-X\right) \mathrm{d} t+\sigma \mathrm{d} z^{*}$, where $\alpha^{*}=\alpha-\lambda, \lambda$ is the market price of risk, $\mathrm{d} z^{*}$ is the increment of a standard Winner process under the equivalent martingale measure.

Let $X_{0}$ represent the logarithm of the current oil price. By using the property of the Ornstein-Uhlenbeck process, we have that under the equivalent martingale measure, $X$ follows a normal distribution, and its expected value and variance at time $t$ are expressed as:

$E\left(X_{t}\right)=\alpha^{*}+\left(X_{0}-\alpha^{*}\right) \mathrm{e}^{-\eta t}=X_{0} \mathrm{e}^{-\eta t}+\alpha^{*}\left(1-\mathrm{e}^{-\eta t}\right)$

$\operatorname{Var}\left(X_{t}\right)=\frac{\sigma^{2}}{2 \eta}\left(1-\mathrm{e}^{-2 \eta t}\right)$

In order to simulate the MRP, Eq. (4) is discretized, and a first-order autoregressive process is obtained then (Dixit and Pindyck 1994; Schwartz 1997):

$X_{t}-X_{t-1}=\alpha^{*}\left(1-\mathrm{e}^{-\eta}\right)+\left(\mathrm{e}^{-\eta}-1\right) X_{t-1}+\epsilon_{t}$

where $\epsilon_{t} \sim N(0, \sigma), \sigma_{\epsilon}^{2}=\frac{\sigma^{2}}{2 \eta}\left(1-\mathrm{e}^{-2 \eta}\right)$

By using the historical data, we obtain:

$X_{t}-X_{t-1}=\hat{a}+\hat{b} X_{t-1}+\epsilon_{t}$

From Eqs. (8) and (9), estimated values of parameters of MRP are obtained:

$\widehat{\alpha^{*}}=-\hat{a} / \hat{b}$

$\hat{\eta}=-\ln (1+\hat{b})$

$\hat{\sigma}=\widehat{\sigma}_{\epsilon} \sqrt{\frac{2 \ln (1+\hat{b})}{(1+\hat{b})^{2}-1}}$

where $\widehat{\sigma}_{\epsilon}$ is the standard error of the regression.

The mean and variance of the normal distribution that the annual logarithm of oil price follows are obtained by substituting the estimated parameters in Eqs. (6) and (7). After the estimation, we conclude that $\sigma$ is $31.28 \%, \eta$ is 0.265 , and $\alpha^{*}$ is $4.17 \mathrm{USD} / \mathrm{barrel}$. Based on the estimated parameters,we apply@RISK to conduct Monte Carlo Simulation, and obtain the random series of oil prices.

\subsection{Cost model}

Costs of OG projects are used to construct production facilities, to maintain production and to repair the environment after the OG fields are abandoned. Costs consist of capital expenditure (Capex), operation expenditure (Opex) and decommissioning expenditure (Decom). Capex is the initial investment of the projects, it is mainly used to construct production facilities. It is classified into 
intangible Capex (ICapex) and tangible Capex (TCapex). Intangible Capex cannot be depreciated, therefore it is accounted as annual costs. However, tangible Capex can be depreciated, and the five-year, straight-line depreciation method is applied (Let $D$ denotes depreciation). Opex is used to maintain production, and can be divided into fixed Opex (FOpex) and variable Opex (Opex $)_{v}$. Fixed Opex refers to the fixed expenditure used for operation and maintenance, while, variable Opex is related to production. Decom refers to the expenditure that is used to restore the environment after the field is abandoned, and it is accounted as the costs at the end of the project. To be specific, the annual cost of an OG field is:

$$
C_{t}=\text { ICapex }_{t}+D_{t}+\text { FOpex }_{t}+\text { Prod }_{t} \times \text { Opex }_{v}+\text { Decom }
$$

\subsection{Income model}

The sales income $(I)$ is the money that comes from the sales of the produced $\mathrm{OG}$, i.e.,

$I_{t}=\operatorname{Prod}_{t} \times P_{t}$

where $P_{t}$ is the average oil price at year $t$.

\subsection{Fiscal terms}

The revenue distribution of OG projects is different in the different fiscal systems. Therefore, three typical fiscal systems and their revenue distribution mechanisms are introduced and relative fiscal terms are set, which lays the foundation for the construction of an economic evaluation model.

\subsubsection{Royalty contract}

With a royalty contract, OG company owns the property of produced OG of the OG field, but needs to investment alone and carry all the risks. Typical revenue distribution of a royalty contract is illustrated in Fig. 4.

Under a royalty contract, the OG project yields sales income after OG resources are produced and sold, then the owner of the project needs to pay the royalty to the government (royalty is calculated by multiplying sales income by a certain percentage). After that, the tax base is obtained when the production costs are deducted, then income tax, dividend tax, and other taxes are calculated based on their corresponding tax rate, and then profit after tax is obtained when the taxes are paid.

Let Royalty denote the paid royalty of OG project under the royalty contract, and $t_{r}$ denotes the royalty tax rate, then:
Royalty $_{t}=I_{t} \times t_{r}$

Let $I T$ represents the income tax of the OG company with a royalty contract, the tax base of income tax is the sales income minus royalty and production costs. Suppose $t_{i t}$ is the corresponding tax rate, then:

$I T_{t}=\left(I_{t}-\right.$ Royalty $\left._{t}-C_{t}\right) \times t_{i t}$

\subsubsection{Production share contract}

With a production share contract, the national OG company of the resource country owns the management and control right of the OG field, and the OG company is responsible for OG production. Typical revenue allocation is shown in Fig. 5.

Under a production share contract, the OG project yields sales income after OG resources are produced and sold, then the owner of the project needs to pay the royalty to the government. There exists the limit of cost oil (namely the Cap) in production share contracts, it is the highest cost that can be recovered from revenue every year. The Cap is obtained as a certain percentage of the sales income minus royalty: if the annual production costs are no larger than the Cap, all production costs are recovered; otherwise, only the Cap of cost oil is recovered, and the unrecovered costs are brought forward to the next year. Profit oil is obtained when the royalty and cost oil is deducted, and it is allocated to the government and OG company based on an agreed percentage. The OG company needs to pay income tax, where the tax base is its share of profit oil.

Let Royalty denotes the paid royalty of the OG project under the production share contract, and $t_{r}$ denotes the royalty tax rate, then:

Royalty $_{t}=I_{t} \times t_{r}$

Let $C O$ represents the cost oil, $C O_{\text {cap }}$ represents the limit of cost oil, and $t_{C O}$ represents the percentage of cost recovery, then:

$$
\begin{aligned}
& C O_{\text {cap }_{t}}=\left(I_{t}-\text { Royalty }_{t}\right) \times t_{C O} \\
& C O_{t}=\min \left(C_{t}+\max \left(C O_{t-1}-C O_{\text {cap }_{t-1}}, 0\right), C O_{\text {cap }_{t}}\right)
\end{aligned}
$$

Let $P O$ denotes the profit oil, $P P O$ denotes the share of the profit oil of the OG company, GPO denotes the share of the profit oil of the government, and $t_{P O}$ represents the percentage of the profit oil of the OG company, then:

$P O_{t}=I_{t}-$ Royalty $_{t}-C O_{t}=P P O_{t}+G P O_{t}$

$P P O_{t}=P O_{t} \times t_{P O}$

Let $I T$ represents the income tax of the OG company with the production share contract, the tax base of income 


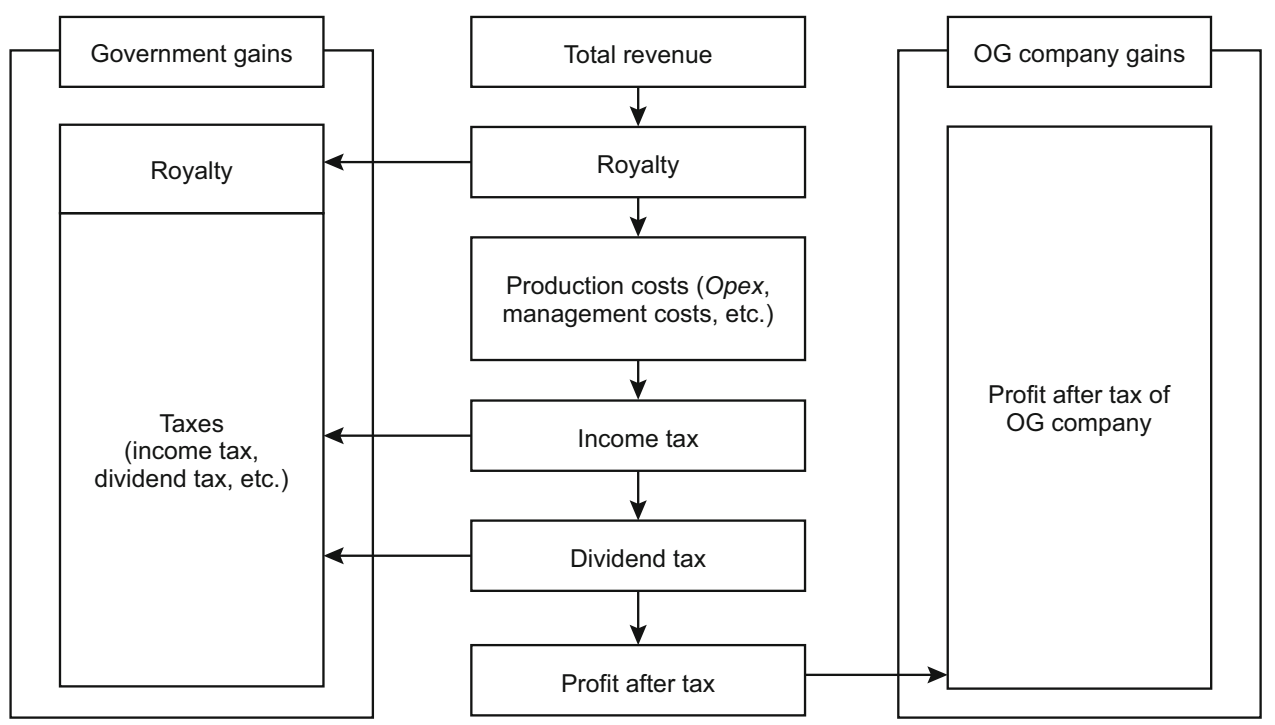

Fig. 4 Revenue allocation under a royalty contract [note: with reference to Mazeel (2010)]

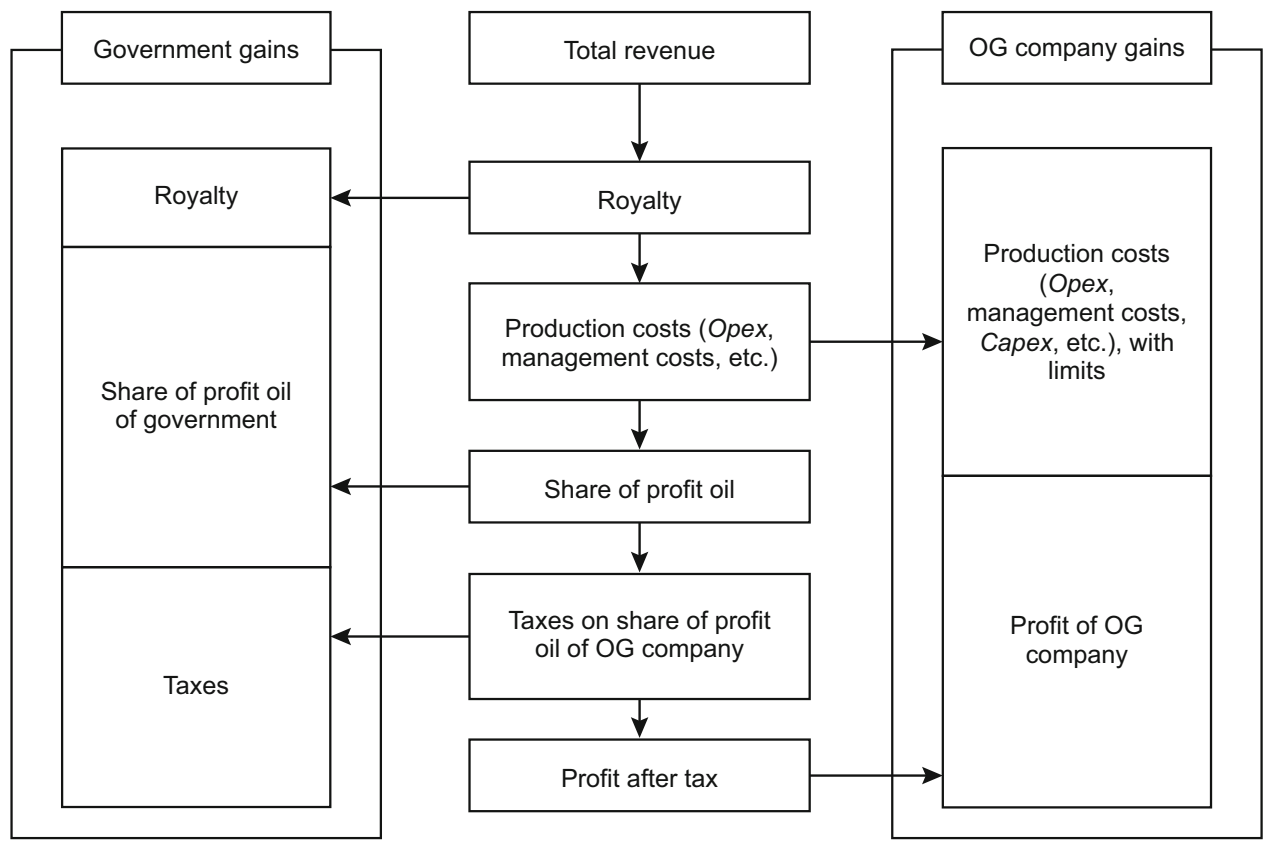

Fig. 5 Revenue allocation under a production share contract [note: with reference to Mazeel (2010)]

tax is the share of profit oil. Suppose $t_{i t}$ is the corresponding tax rate, then:

$I T_{t}=P P O_{t} \times t_{i t}$

\subsubsection{Service contract}

The core concept of a service contract is the resource country regards the production process of the OG company as a service and pays for the service, but the resource country owns the property of the produced OG resources. A service contract includes a risk service contract, pure service contract, and mixed service contract. The difference between a risk service contract and a pure service contract is that the OG company needs to carry the risks: under a risk service contract, the OG company needs to undertake all the Capex, Opex and risks, and can recover the investment and acquire compensation fee after the field starts to produce OG; while, under a pure service contract, the OG company is not responsible for the exploration and production risks, and only gains the compensation fee by providing the production facilities and operation. A mixed service contract is the combination of a risk service 
contract and a pure service contract, the OG company should carry certain risks, but it can recover its investment and receive compensation when the OG resources are produced. Typical revenue distribution of a service contract is illustrated in Fig. 6.

A risk service contract is analyzed in this paper. Under a risk service contract, the OG project yields sales income after OG resources are produced and sold. Afterward the limit of cost oil is obtained as a certain percentage of the sales income: if the annual production costs are no larger than the limit, all production costs are recovered; otherwise, only the limit of cost oil is recovered (the Opex are preferentially recovered), and the unrecovered costs are carried forward to the next year. The compensation fee is a certain percentage (compensation rate) of the difference between the limit of cost oil and the recovered costs. The OG company needs to pay income tax on the tax base of its compensation.

Let $C O$ represents the cost oil, $C O_{\text {cap }}$ represents the limit of cost oil, and $t_{C O}$ represents the percentage of cost recovery, then:

$$
\begin{aligned}
& C O_{\text {cap }_{t}}=I_{t} \times t_{C O} \\
& C O_{t}=\min \left(C_{t}+\max \left(C O_{t-1}-C O_{\text {cap }_{t-1}}, 0\right), C O_{\text {cap }_{t}}\right)
\end{aligned}
$$

it should be noticed that if the production costs are larger than the limit of cost oil, Opex is firstly recovered, Capex and Decom are recovered then, and the unrecovered costs are carried forward to the next year.

Let $C O M$ denotes compensation fee, and $t_{C O M}$ denotes the compensation rate, then:

$\mathrm{COM}_{t}=\max \left(\mathrm{CO}_{\text {Cap }_{t}}-\mathrm{CO}_{t}, 0\right) \times t_{C O M}$
Let $I T$ represents the income tax of the OG company with a risk service contract, the tax base of income tax is the compensation fee. Suppose $t_{i t}$ is the corresponding tax rate, then:

$I T_{t}=C O M_{t} \times t_{i t}$

\subsection{Projects value model}

The net present value $(N P V)$ of the $\mathrm{OG}$ project is applied to estimate the project value. $N P V$ refers to the aggregate values of net cash flows which are discounted to year 0 , to be specific:

$N P V=\sum_{t=0}^{T_{d}} \frac{N C F_{t}}{(1+r)^{t}}$

where $N C F_{t}$ is the net cash flows in year $t, r$ is the discount rate, $T_{d}$ is the project life cycle.

\subsection{Projects VaR}

By applying the probabilistic model, the NPV frequency histogram of the OG projects is obtained. After that, a certain probability can be selected, and the corresponding threshold can be calculated. To be specific:

$\operatorname{Prob}(N P V \leq \mathrm{VaR})=1-\alpha$ or $\operatorname{Prob}(N P V \geq \mathrm{VaR})=\alpha$

where $\operatorname{Prob}()$ denotes the probability that the project's $N P V$ is higher than or lower than the threshold, $1-\alpha$ or $\alpha$ denotes the corresponding probability.

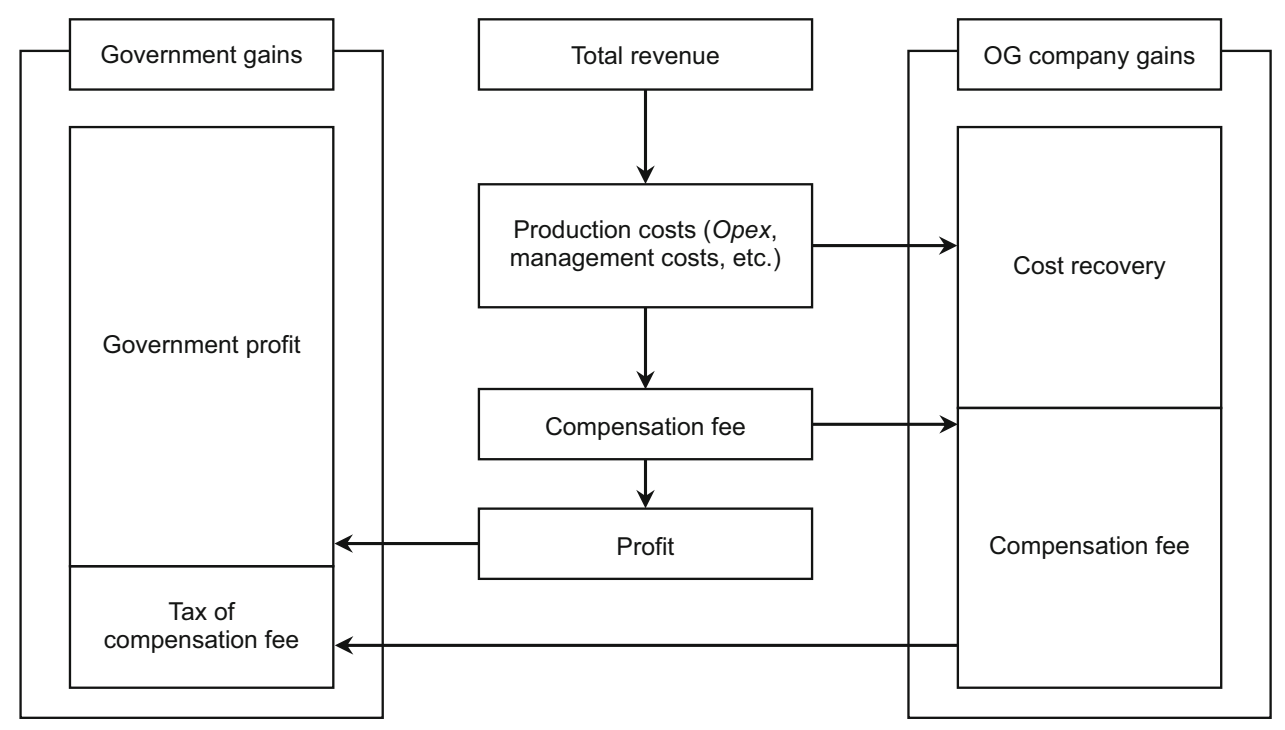

Fig. 6 Revenue allocation under a service contract [note: with reference to Mazeel (2010)] 


\section{Empirical analysis}

In order to conduct the empirical analysis, an international oil project is used as an example in this paper. Three economic evaluation models and corresponding probabilistic models of the different fiscal systems are established in Excel. @RISK is applied to conduct Monte Carlo Simulation, and NPV frequency histograms of the $\mathrm{OG}$ company in different fiscal systems are obtained, and then project risks are measured.

\subsection{Parameters of economic evaluation}

Suppose that the international oil project is a new project for the OG company, its life cycle is 11 years. ${ }^{1}$ Given that international OG projects face resource risks and economic risks, oil originally in place (OOIP), variable Opex (Opex per barrel), and oil price are assumed to be stochastic variables. As for the policy risks, royalty rate, cost recovery rate, and compensation rate are selected as stochastic variables in the royalty contract, production share contract, and service contract, respectively, because these three variables are the core fiscal terms in the three fiscal systems. As for OOIP, with reference of Jakobsson et al. (2012), we assume it follows a lognormal distribution with a range between 0 and positive infinity. As for Opex per barrel, with reference of Falconett and Nagasaka (2010), we assume it follows a triangular distribution. As for royalty rate, cost recovery rate, and compensation rate, we assume they follow uniform distributions. As for oil price, we assume it is a Mean-Reverting Process. Stochastic variables and their assumptions are listed in Table 1.

Apart from the six parameters above, the other related parameters are assumed to be fixed variables. Some of the values of the other parameters are provided by the project owner, and some are based on the existing literature (Welkenhuysen et al. 2017; Wang et al. 2012), which is listed in Table 2.

\subsection{Results analysis and discussion}

After economic evaluation models of the different fiscal systems are established in Excel, @RISK is applied to conduct 10,000 iterations based on the assumptions of stochastic variables, and the simulation results of $N P V \mathrm{~s}$ in the three models are obtained. The simulation results are analyzed first, then the impacts of oil price, OOIP, and Opex per barrel on NPV is compared. Finally, the impacts of $N P V$ distribution on decision making is investigated.

\footnotetext{
1 The project is owned by a national petroleum company of China. The related information is provided by this company.
}

Table 1 Stochastic variables, their distribution and distribution parameters

\begin{tabular}{|c|c|c|c|c|c|}
\hline \multirow{2}{*}{\multicolumn{2}{|c|}{$\begin{array}{l}\text { Variables } \\
\text { A) Lognormal distribution }\end{array}$}} & \multicolumn{4}{|c|}{ Parameters } \\
\hline & & \multicolumn{2}{|l|}{ Unit } & \multicolumn{2}{|l|}{ Mean } \\
\hline \multicolumn{2}{|l|}{ 1. $O O I P$} & \multicolumn{2}{|c|}{10 million barrels } & 5 & 0.8 \\
\hline $\begin{array}{l}\text { B) Triangle } \\
\text { distribution }\end{array}$ & Unit & Minimum & $\begin{array}{l}\text { Most } \\
\text { possible } \\
\text { value }\end{array}$ & & imum \\
\hline $\begin{array}{l}\text { 2. Opex per } \\
\text { barrel }\end{array}$ & $\begin{array}{l}\text { US dollar/ } \\
\text { barrel }\end{array}$ & 10 & 14 & 15 & \\
\hline \multicolumn{2}{|c|}{ C) Uniform distribution } & Unit & Minimum & \multicolumn{2}{|c|}{ Maximum } \\
\hline \multicolumn{2}{|c|}{ 3. Royalty rate } & $\%$ & 20 & \multicolumn{2}{|c|}{40} \\
\hline \multicolumn{2}{|c|}{ 4. Cost recovery rate } & $\%$ & 50 & \multicolumn{2}{|c|}{70} \\
\hline \multicolumn{2}{|c|}{ 5. Compensation rate } & $\%$ & 70 & \multicolumn{2}{|c|}{90} \\
\hline \multicolumn{3}{|c|}{ D) Mean reversion process } & Unit & \multicolumn{2}{|r|}{ Value } \\
\hline \multicolumn{2}{|c|}{ 6. Original oil price } & & \multicolumn{2}{|c|}{$\begin{array}{l}\text { US dollar/ } \\
\text { barrel }\end{array}$} & 43.29 \\
\hline \multicolumn{2}{|c|}{ Std. of oil price } & & $\%$ & & 31.28 \\
\hline \multicolumn{3}{|c|}{ Speed of reversion } & \multicolumn{3}{|r|}{0.265} \\
\hline \multicolumn{3}{|c|}{$\begin{array}{l}\text { Logarithm of long-term equilibrium oil } \\
\text { price }\end{array}$} & $\begin{array}{l}\text { US dollar/ } \\
\text { barrel }\end{array}$ & & 4.17 \\
\hline
\end{tabular}

(1) Means of OOIP, Opex per barrel, Royalty rate, Cost recovery rate and Compensation rate is provided by the project owner. Other parameters of the distributions are with reference to Jakobsson et al. (2012) and Falconett and Nagasaka (2010), respectively. (2) Parameters of oil price are calculated by the authors

\subsubsection{Simulation results}

4.2.1.1 Evaluation results of royalty contract The NPV frequency histogram of the royalty contract is shown in Fig. 7a. The simulation results indicate that the mean NPV of the royalty contract is 17.2 million US dollars, and Std is 42.4. According to the simulation results, it is possible that the $N P V$ of royalty contract is negative (the probability is $35.1 \%$ ), namely the probability that investors would lose their investment is $35.1 \%$. Similarly, from the frequency histogram, we are $59.9 \%$ confident that the NPV falls in the range between 0 and 90.7 million US dollars, and 5\% confident that the NPV exceeds 90.7 million US dollars.

In order to analyze the impacts of different stochastic variables on the $N P V$ of the royalty contract, we conduct an analysis of the contribution to the variance of $N P V$, as shown in Fig. 7b. From Fig. 7b, we conclude that the randomness of oil price has the greatest impact, the royalty rate ranks second; OOIP also has a certain impact, while Opex per barrel has a small impact. Under the assumed royalty contract in this paper, when the produced oil is sold and the sales income is obtained, the OG company needs to 
Table 2 Other parameters related to economic analysis

\begin{tabular}{lll}
\hline Variables & Parameters \\
\cline { 2 - 3 } & Unit & Value
\end{tabular}

\section{A) Parameters of production curve}

1. Recovery rate

$\%$

46

2. Mean

2

3. Std.

4. Project life cycle

Year

11

B) Parameters of investment

$\begin{array}{llr}\text { 5. Intangible Capex } & \text { Thousand dollars } & 46,000 \\ \text { 6. Tangible Capex } & \text { Thousand dollars } & 96,000\end{array}$

C) Parameters of Opex

7. Fixed Opex

Thousand dollars

15,000

D) Parameters of Decom

8. Decommissioning expenditure

Thousand dollars

E) Parameters of royalty contract

9. Income tax rate

$\%$

F) Parameters of production share contract

10. Royalty rate

11. Profit oil percentage of the OG company

12. Income tax rate

$\begin{array}{ll}\% & 5 \\ \% & 45 \\ & 30 \\ \% & \\ \% & 75 \\ & 30\end{array}$

G) Parameters of service contract
13. Cost recovery rate
30
14. Income tax rate

$\%$
12

$\%$

Some of the parameters are provided by the project owner, and some are with reference to Wang et al. (2012) and Welkenhuysen et al. (2017) (a) NPV frequency histogram of the royalty contract

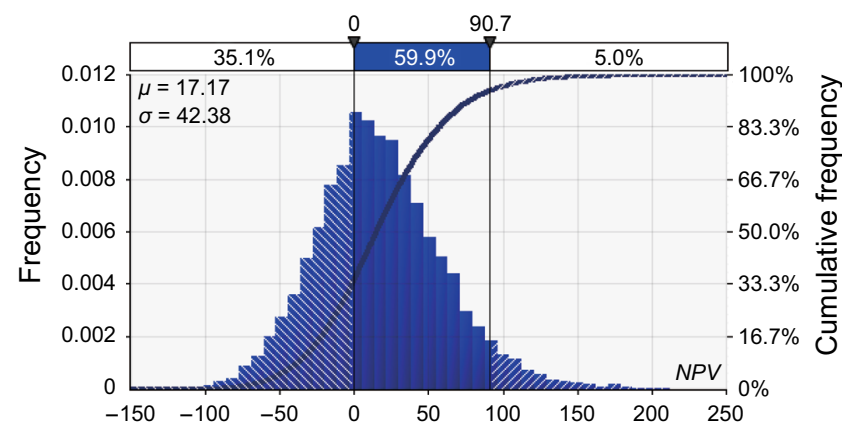

Fig. 7 Results of economic analysis for the royalty contract

pay royalty to the resource country based on the sales income. Therefore, the royalty rate greatly influences the surplus revenue of the royalty contract, and will have a great impact on the NPV. The impacts of oil price, OOIP, Opex per barrel are analyzed later.

4.2.1.2 Evaluation results of the production share contract The NPV frequency histogram of the production (b) Contribution to the variance of NPV

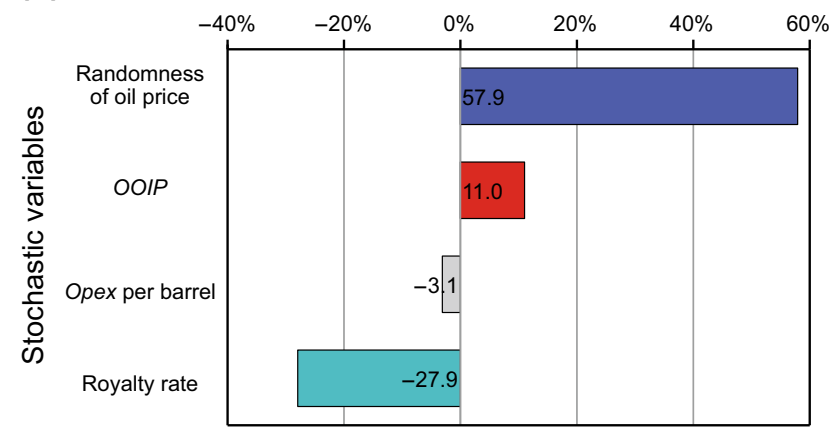

share contract is shown in Fig. 8a. The simulation results show that the mean NPV of the production share contract is 19.1 million US dollars, and Std is 39.4. According to the simulation results, the probability that investors would lose their investment is $32.5 \%$; the probability that the NPV falls in the range between 0 and 81.5 million US dollars is $62.5 \%$; the probability that the $N P V$ exceeds 81.5 million US dollars is $5 \%$. 
(a) NPV frequency histogram of the production share contract

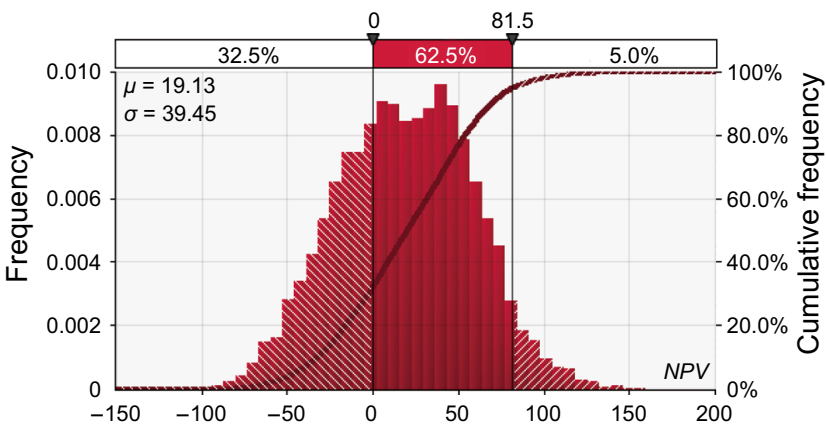

Fig. 8 Results of economic analysis for the production share contract

Contribution to the variance of $N P V$ under the production share contract is shown in Fig. 8b. According to Fig. 8b, we conclude that the oil price randomness has the greatest impact, OOIP ranks second; the cost recovery rate also has a great impact, while Opex per barrel has a small impact. Under the assumed production share contract in this paper, sales income is assessed when the produced oil is sold, then the royalty is paid. After that, the limit of cost oil is decided by the net income (i.e., sales income minus royalty) and cost recovery rate, and then the actual recovered cost is determined by available and forwarded production costs. Therefore, the cost recovery rate has a great influence on $N P V$, but the influence depends on the cost recovery mechanism. Overall, the influence of the cost recovery rate is not direct, consequently, its impact is relatively low. The impacts of oil price, OOIP, Opex per barrel are analyzed later.

4.2.1.3 Evaluation results of the service contract The $N P V$ frequency histogram of the service contract is shown in Fig. 9a. The simulation results show that the mean $N P V$ of the service contract is 12.3 million US dollars, and Std is 39.9. According to the simulation results, there is $36.7 \%$ assurance that the investors would lose all their investment; there is a $58.3 \%$ assurance that the $N P V$ falls in the range

(a) NPV frequency histogram of the service contract

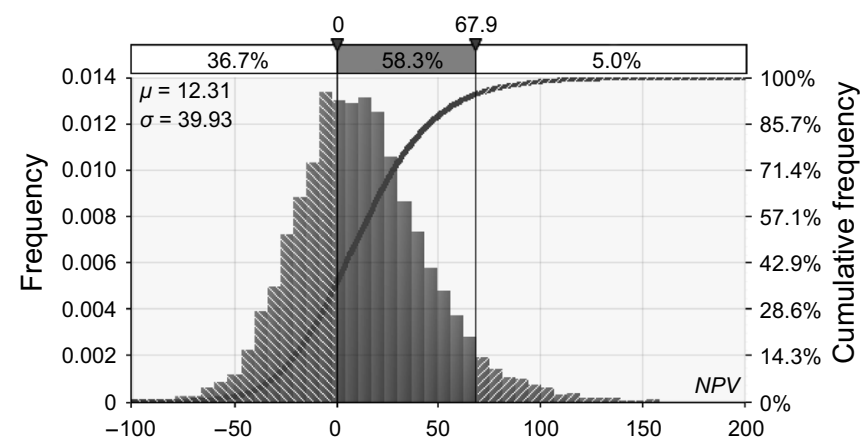

(b) Contribution to the variance of NPV

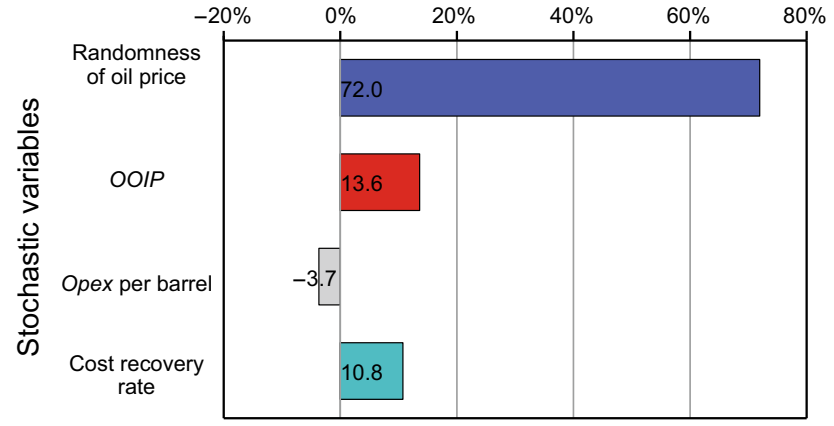

between 0 and 67.9 million US dollars; there is $5 \%$ probability that the NPV exceeds 67.9 million US dollars.

Contribution to the variance of $N P V$ under the service contract is shown in Fig. 9b. As shown in Fig. 9b, the randomness of oil price has the greatest impact, OOIP ranks second; while Opex per barrel and compensation rate have small impacts. Under the assumed risk service contract in this paper, the OG company has two kinds of income, namely the recovered costs (Opex, Capex, and Decom) and the compensation fee. The compensation fee is based on the difference between the limit of cost oil and the actual recovered cost, therefore, the more costs are recovered, the lower the compensation fee obtained. Overall, the compensation fee is a small part of the cash flows of the OG company, therefore, it has little impact on $N P V$. The impacts of oil price, OOIP and Opex per barrel are analyzed later.

\subsubsection{Comparison of the impacts of oil price, OOIP, and Opex per barrel on NPV}

Oil price has a significant impact on the $N P V$ because of two factors. Firstly, the oil price has a direct influence on the total revenue of the project, and is a key factor in determining annual cash flows. Secondly, oil price is

(b) Contribution to the variance of NPV

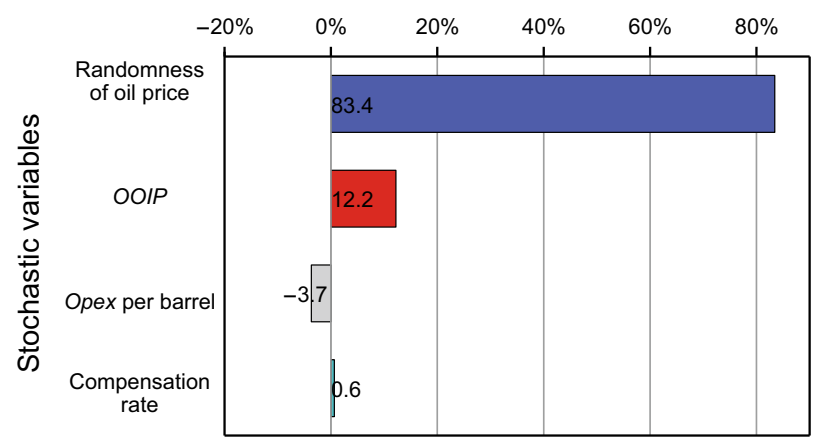

Fig. 9 Results of economic analysis for the service contract 
volatile, and has a great contribution to the variance of $N P V$. OOIP also has a great influence on the $N P V$, and its impact on the $N P V$ is similar to that of oil price. However, its impact on the annual cash flow is transmitted by the production curve, and not as direct as oil price, thus, its impact on the $N P V$ is smaller than oil price's. Opex per barrel also influences the $N P V$. But as its value is small and the variation range is narrow, its impact on the annual cash flow is not large. Consequently, its impact on the $N P V$ is relatively weak.

As shown in Figs. 7b, 8b, and 9b, both oil price and $O O I P$ have great impacts on the NPV. In order to compare their impacts, a bubble chart is applied to analyze the relationship among oil price, OOIP and NPV. The bubble charts of the three different fiscal systems are similar, and we take the service contract as an example to analyze, which is shown in Fig. 10a (the bubble charts of the royalty and production share contracts are placed in Fig. 10b, c, respectively). In order to divide the oil price and OOIP into the high scenario and low scenario, the bubble chart is partitioned into 4 quadrants. Quadrants I-IV represent high oil price and high $O O I P$ scenario, high oil price and low $O O I P$ scenario, low oil price and low $O O I P$ scenario, and low oil price and high OOIP scenario, respectively. By comparing the bubble size of quadrants I and III, it is easy to infer $N P V$ has a positive relationship with both oil price and OOIP. Meanwhile, by observing the bubble size of quadrants II and IV, we conclude the $N P V$ in high oil price and low $O O I P$ scenario is higher than the counterpart in low oil price and high $O O I P$ scenario, thus, it can be inferred that the impacts of the oil price on the $N P V$ are greater than that of $O O I P$.

Both oil price and Opex per barrel have influences on the $N P V$, but their relationships are different. In order to compare their impacts, bubble charts are shown for visual comparison. The relationship among the oil price, Opex per barrel and the $N P V$ of the service contract is shown in Fig. 11a (the bubble charts of the royalty contract and the production share contract are shown in Fig. 11b, c, respectively). By comparing the bubble size of quadrants I and III, it can be inferred that the positive impacts of a rise of oil price on the $N P V$ are apparently stronger than the negative impacts of a rise of Opex per barrel. The results are similar to that in the other fiscal systems, and we do not reiterate them here.

Both OOIP and Opex per barrel have influences on the $N P V$, but their relationships are different. In order to compare their impacts, the bubble charts are shown. The relationship among the OOIP, Opex per barrel and the NPV of service contract is shown in Fig. 12a (the bubble charts of the royalty contract and the production share contract are shown in Fig. 12b, c, respectively). By comparing the bubble size of quadrants I and III, it can be inferred that the (a) Service contract

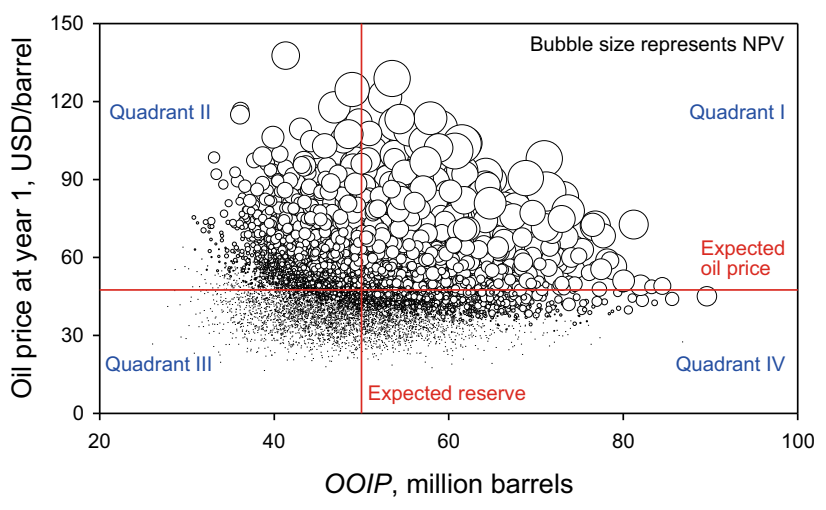

(b) Royalty contract

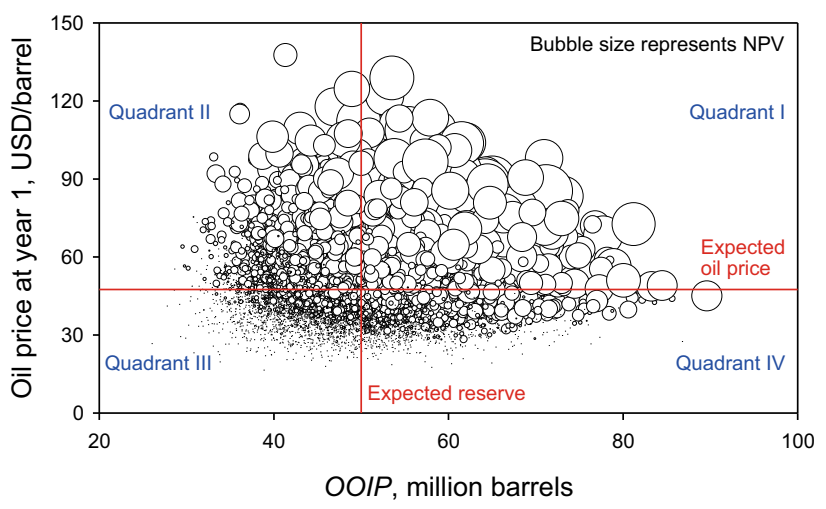

(c) Production contract

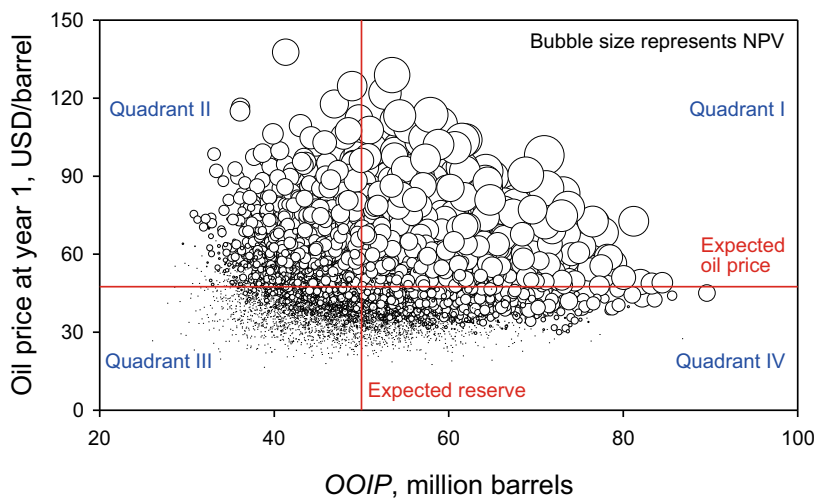

Fig. 10 Relationship among $N P V, O O I P$ and oil price of the three contracts. Notes: Quadrant I represents the areas with high oil price and big OOIP, Quadrant II denotes the areas with high oil price and small $O O I P$, Quadrant III represents the areas with low oil price and small OOIP, Quadrant IV denotes the areas with low oil price and big OOIP

positive impacts of the raise of $O O I P$ on the $N P V$ are stronger than the negative impacts of the rise of Opex per barrel. $^{2}$ The results are similar in the other fiscal systems, we will not reiterate them here.

${ }^{2}$ The volatility of the $O O I P$ is assumed to be low in this paper,
therefore, its impact on the $N P V$ is relatively weak, and the bubble 
(a) Service contract

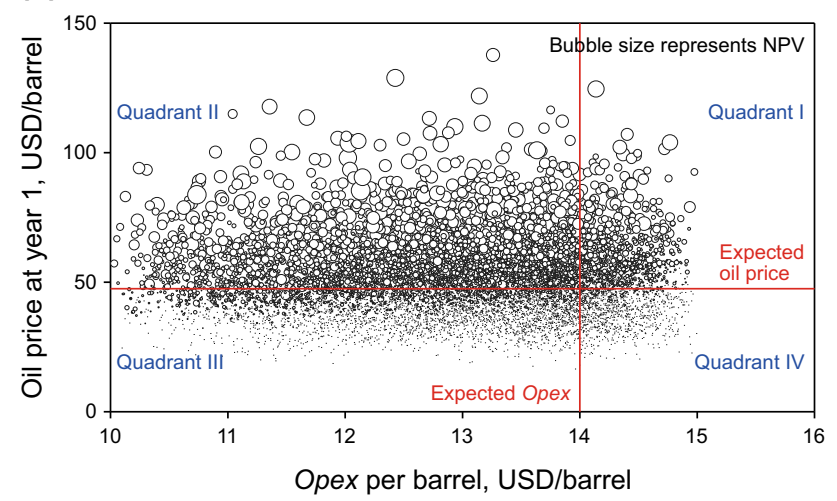

(b) Royalty contract

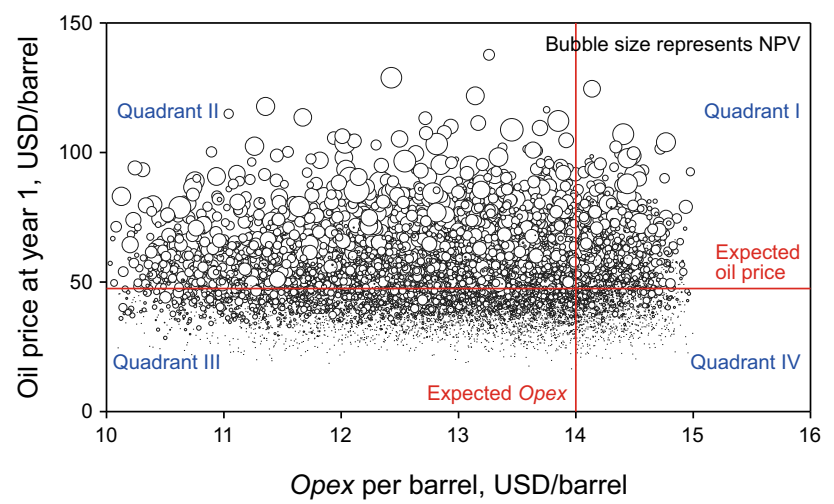

(c) Production share contract

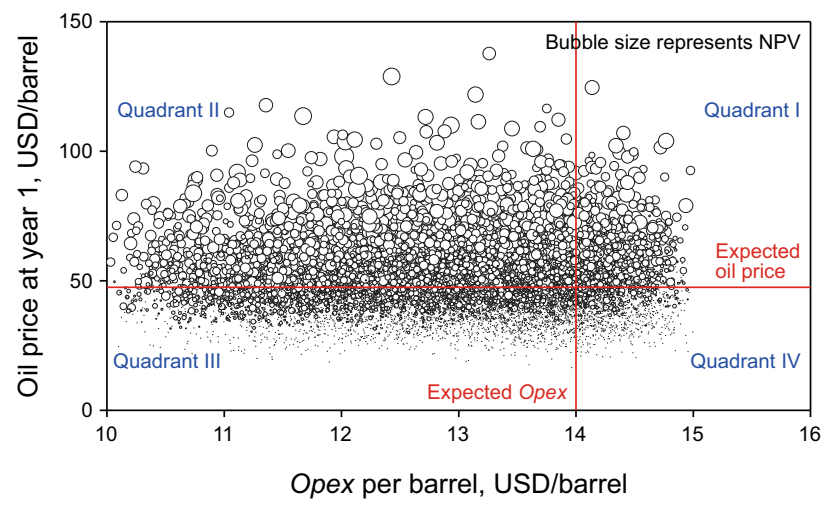

Fig. 11 Relationship among $N P V$, Opex per barrel and oil price of the three contracts. Notes: Quadrant I represents the areas with high oil price and high Opex, Quadrant II denotes the areas with high oil price and low Opex, Quadrant III represents the areas with low oil price and low Opex, Quadrant IV denotes the areas with low oil price and high Opex

Footnote 2 continued

size of quadrant I is just a little larger than that of quadrant III. Once the volatility of OOIP is raised, OOIP's impacts on the $N P V$ will obviously be enhanced. (a) Service contract

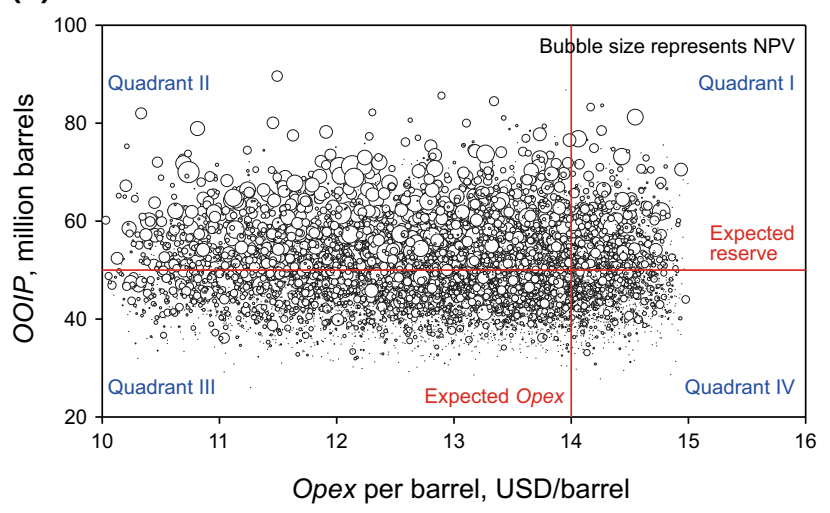

(b) Royalty contract

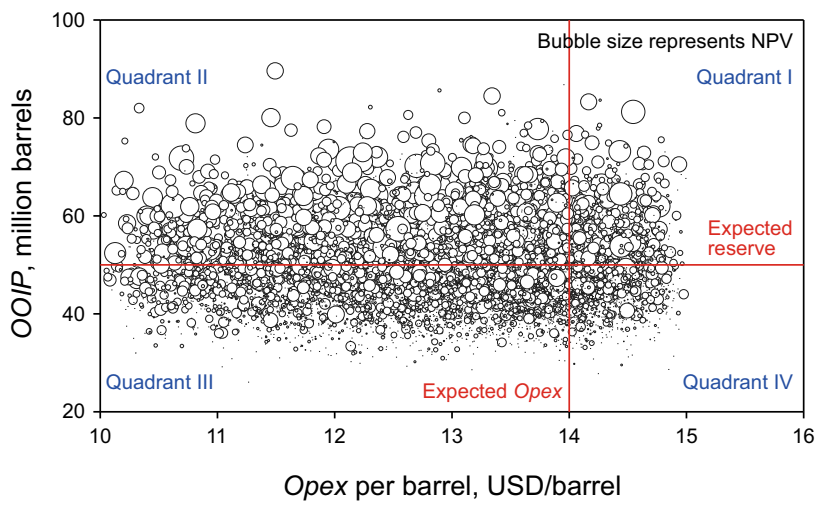

(c) Production share contract

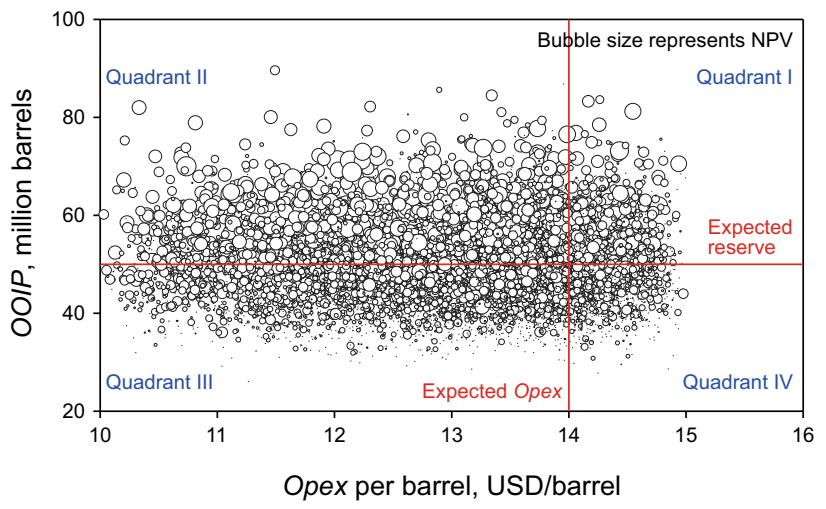

Fig. 12 Relationship among $N P V$, Opex per barrel and OOIP of the three contracts. Notes: Quadrant I represents the areas with big OOIP and high Opex, Quadrant II denotes the areas with big OOIP and low Opex, Quadrant III represents the areas with small OOIP and low Opex, Quadrant IV denotes the areas with small OOIP and high Opex

\subsubsection{Decision making and NPV distribution}

The probabilistic model can help decision makers acknowledge the possible NPV distribution of a project, which is very important for them. Traditional economic evaluation method can only provide the decision makers with one $N P V$ value. In the real world with many 
uncertainties, it is very risky for the decision makers to decide based on just one NPV estimate because it is easy to cause deviation. Taking the service contract in this paper as an example, the traditional economic evaluation model indicates that the $N P V$ of the project is 6.00 million US dollars. However, once the risk factors are considered, there is $45 \%$ assurance that the project $N P V$ is less than 6.00 million US dollars. Decision makers can link the possible $N P V \mathrm{~s}$ with probabilities by using a probabilistic model, which is helpful for making the right decision. Besides, uncertain factors of the economic evaluation model are fully considered in the probabilistic model, therefore it is useful to avoid the possible losses caused by the unexpected emergence of uncertain factors.

In order to assist the decision makers to make sensible decisions, we can fit the simulation results and obtain the fitted probabilistic curve. When making decisions, decision makers can choose a suitable confidence level based on their ability to cope with risks, and then obtain their VaR according to the fitted probabilistic curve and confidence level, and decide to invest or not based on VaR. The fitted $N P V$ distribution curve of the service contract is shown in Fig. 13. The fitting result indicates that the $N P V$ of the service contract follows a lognormal distribution with a mean of 244 (million US dollars), a Std of 31.8, and a shifted domain of -232 (million US dollars), to be specific:

$f(x-232.04)=\frac{1}{0.13 * x \sqrt{2 \pi}} \mathrm{e}^{-\frac{1}{2}\left[\frac{[\ln x-5,49}{0.13}\right]^{2}}$

The fitted $N P V$ distribution curve of the royalty contract is shown in Fig. 14. The fitting result indicates that the $N P V$ of the royalty contract follows an Inverse Gaussian distribution with a mean of 367 (million US dollars), a shape parameter of 27,656 , and a shifted domain of -350 (million US dollars), to be specific:

$f(x-350.01)=\sqrt{\frac{27655.6}{2 \pi x^{3}}} \mathrm{e}^{-\left[\frac{27655.6(x-367.19)^{2}}{260655.99 x}\right]}$

The fitted NPV distribution curve of the production share contract is shown in Fig. 15. The fitting result indicates that the $N P V$ of the production share contract follows a Weibull distribution with a shape parameter of 3.85 , a scale parameter of 150.6, and a shifted domain of -117 (million US dollars), to be specific:

$f(x-117.04)=\frac{3.85 x^{2.85}}{244157870} \mathrm{e}^{-(x / 150.58)^{3.85}}$

Suppose that a decision maker with the service contract, can carry $40 \%$ risk at most. Based on this probability and the fitted distribution curve of the service contract, it can be inferred that the probability that the $N P V$ is less than 2.40 million US dollars is $40 \%$, while the probability that the

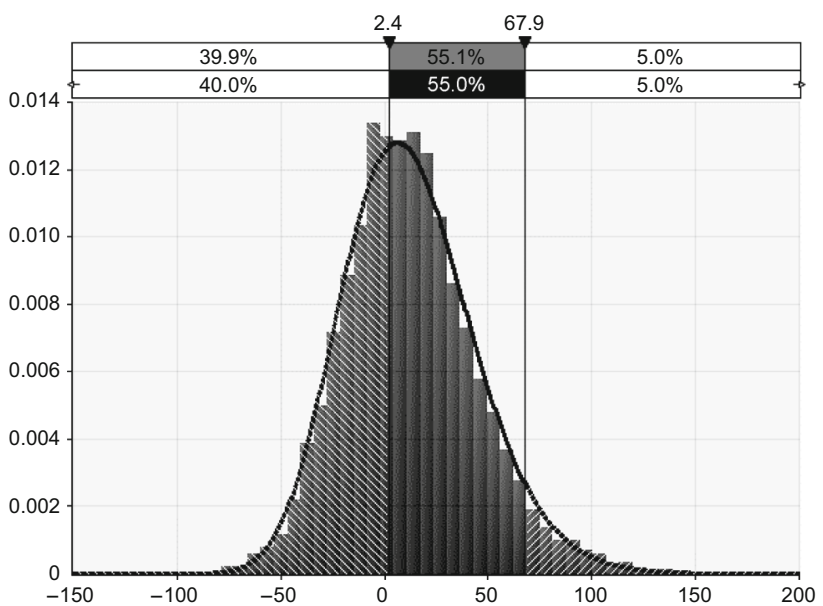

Fig. 13 Fitting of NPV's distribution curve for the service contract

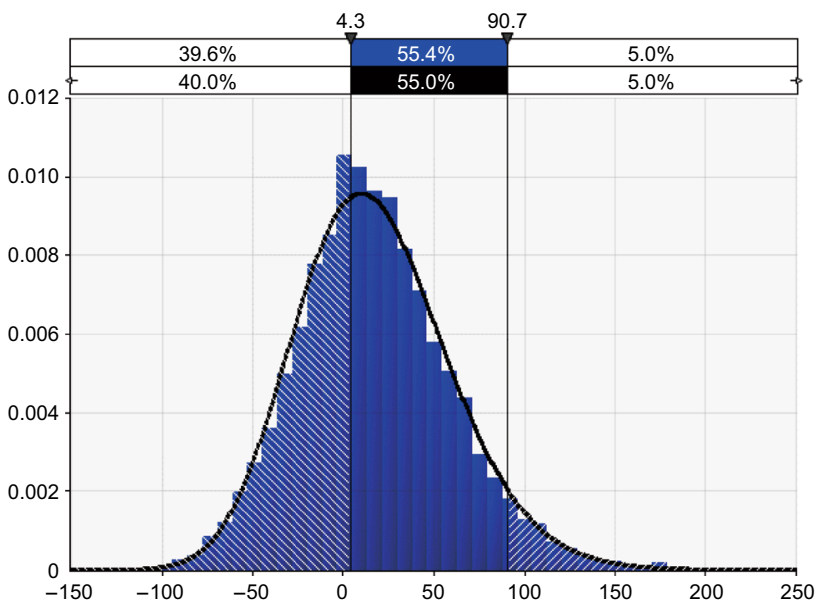

Fig. 14 Fitting of NPV's distribution curve for the royalty contract

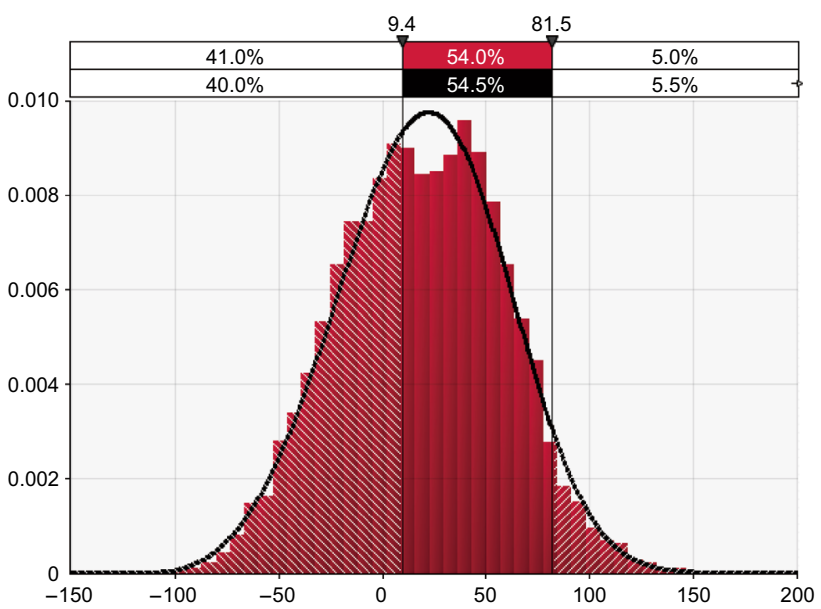

Fig. 15 Fitting of NPV's distribution curve for the production share contract 
$N P V$ surpass 2.40 million US dollars is $60 \%$. Therefore, the decision maker can choose to invest in this project.

\section{Conclusions and discussions}

This paper applies a probabilistic model to analyze the impacts of risk factors embedded in international $\mathrm{OG}$ projects on the project's $N P V$. The production curve, the stochastic process of oil price, production costs, sales income, and fiscal terms are first studied, thereafter traditional economic evaluation models are established based on the studies. Later on, variables in the traditional economic evaluation models are divided into fixed variables and stochastic variables. As for stochastic variables, we apply the Monte Carlo Simulation method to simulate their randomness. Consequently, probabilistic models are set up. Finally, this paper take an international oil project as an example to research the $N P V$ frequency histogram of the project under a royalty contract, production share contract and a service contract. Several conclusions are achieved after these analyses:

(1) Risks have great impacts on the project values, decision makers may bias their decision if they overlook risks. Taking the service contract as an example, the traditional economic evaluation model indicates that the NPV of the project is 6.00 million US dollars. However, once the risk factors are considered, there is $45 \%$ assurance that the project $N P V$ is less than 6.00 million US dollars. If risks are neglected, the actual $N P V$ of the project may be far less than the results of traditional economic evaluation model, which will cause decision deviation.

(2) A simulation method is applied to simulate the stochastic distribution of risk factors in the probabilistic model. Therefore, probability is related to the project's $N P V$, which overcomes the inherent limitation of the traditional economic evaluation method. The traditional economic evaluation model is based on rigid assumptions, and can only provide one $N P V$. Meanwhile, a probabilistic model can provide the $N P V$ frequency histogram, and overcome the intrinsic defect (namely that uncertainties are neglected) of the traditional economic evaluation model.

(3) $\mathrm{VaR}$ is a straightforward risk measure tool, like in the service contract, according to the fitted probability density curve, it can be inferred that the probability that the $N P V$ is large than 2.40 million US dollars is $60 \%$. This straightforward index can help decision makers to decide. Therefore, in order to assist decision making, VaR can be applied to measure the risks of international oil and gas projects.

In order to conduct a more precise quantitative risk analysis of international OG projects, and to investigate the impacts of different risk factors on the $N P V$ of the international OG projects, this paper proposes a research framework, namely the probabilistic model. Probabilistic model is based on traditional economic evaluation models. However, some variables are recognized as stochastic variables, and a Monte Carlo Simulation method is applied to simulate these variables. Therefore, the distribution of $N P V$ of international $\mathrm{OG}$ projects can be obtained. By using VaR, the probability that the NPV exceeds a certain threshold value can be estimated. The results can help decision makers to acknowledge the risks of the international OG projects. Compared with previous studies, this paper provides a standard analysis framework which other scholars can use when they conduct a risk analysis of international OG projects. For example, although the simulation method is applied in the economic evaluation process of OG projects, there is no consensus about what kind of risks are embedded in the international OG projects. With reference to previous studies, we propose that resources risks, economic risks and policy risks need to be considered. Besides, $\mathrm{VaR}$ is introduced to the probabilistic model, which provides a new method for the risk measurement of international OG projects.

The case study is used to illustrate how to use a probabilistic model. Therefore, when other scholars use the probabilistic model, they can change the assumptions according to the information of their projects. For example, if the project is not a new project, we can use the production curve and some other information, such as the years of production, to calculate the production for each year. The shortcoming of this paper is that some assumptions are rough, such as $O O I P$. With reference to Jakobsson et al. (2012), we assume that it follows a lognormal distribution. However, OOIP is a very complicated resource indicator, it is decided by many factors, such as the degree of porosity, block size, the effective thickness of reservoirs and so on. Although different experts may have different assumptions about the distribution of $O O I P$, they have a consensus that $O O I P$ is a stochastic variable. Therefore, when using the probabilistic model to conduct a risk analysis of international OG projects, experts change assumptions based on the reality of their projects and their experience.

Acknowledgements This work is supported by the Young Fund of Shanxi University of Finance and Economics (No. QN-2018002), National Natural Science Foundation of China (No. 71774105), the Fund for Shanxi Key Subjects Construction (FSKSC) and Shanxi Repatriate Study Abroad Foundation (No. 2016-3).

Open Access This article is distributed under the terms of the Creative Commons Attribution 4.0 International License (http://creative commons.org/licenses/by/4.0/), which permits unrestricted use, distribution, and reproduction in any medium, provided you give appropriate credit to the original author(s) and the source, provide a 
link to the Creative Commons license, and indicate if changes were made.

\section{References}

Adams A, Gibson C, Smith RG. Probabilistic well-time estimation revisited. SPE Drill Complet. 2010;25(4):472-99. https://doi. org/10.2118/119287-PA.

Arps JJ. Analysis of decline curves. Trans AIME. 1945;160(1):228-47. https://doi.org/10.2118/945228-G.

Dalton GJ, Alcorn R, Lewis T. A 10-year installation program for wave energy in Ireland: a case study sensitivity analysis on financial returns. Renew Energy. 2012;40(1):80-9. https://doi. org/10.1016/j.renene.2011.09.025.

Dixit AK, Pindyck RS. Investment under uncertainty. Princeton: Princeton University Press; 1994.

Dong Z, Holditch S, McVay D. Resource evaluation for shale gas reservoirs. SPE Econ Manag. 2013;5(1):5-16. https://doi.org/10. 2118/152066-pa.

Falconett I, Nagasaka K. Comparative analysis of support mechanisms for renewable energy technologies using probability distributions. Renew Energy. 2010;35(6):1135-44. https://doi. org/10.1016/j.renene.2009.11.019.

Fetkovich MJ. Decline curve analysis using type curves. J Pet Technol. 1980;32(6):1065-77. https://doi.org/10.2118/4629-PA.

Gass V, Strauss F, Schmidt J, Schmid E. Assessing the effect of wind power uncertainty on profitability. Renew Sustain Energy Rev. 2011;15(6):2677-83. https://doi.org/10.1016/j.rser.2011.01.024.

Goel V, Grossmann IE. A stochastic programming approach to planning of offshore gas field developments under uncertainty in reserves. Comput Chem Eng. 2004;28(8):1409-29. https://doi. org/10.1016/j.compchemeng.2003.10.005.

Hertz DB. Risk analysis in capital investment. Harv Bus Rev. 1964;57(5):169-81.

Höök M, Aleklett K. A decline rate study of Norwegian oil production. Energy Policy. 2008;36(11):4262-71. https://doi. org/10.1016/j.enpol.2008.07.039.

Hu XD, Shen HC. Basis for risk management. Nanjing: Southeast University Press; 2001 (in Chinese).

Jakobsson K, Bentley R, Söderbergh B, Aleklett K. The end of cheap oil: Bottom-up economic and geologic modeling of aggregate oil production curves. Energy Policy. 2012;41:860-70. https://doi. org/10.1016/j.enpol.2011.11.073.

Khadem MMRK, Piya S, Shamsuzzoha A. Quantitative risk management in gas injection project: a case study from Oman oil and gas industry. J Ind Eng Int. 2017. https://doi.org/10.1007/ s40092-017-0237-3.

Lin J, de Weck O, de Neufville R, Yue HK. Enhancing the value of offshore developments with flexible subsea tiebacks. J Pet Sci Eng. 2013;102:73-83. https://doi.org/10.1016/j.petrol.2013.01.003.

Liu M, Wang Z, Zhao L, Pan Y, Xiao F. Production sharing contract: an analysis based on an oil price stochastic process. Pet Sci. 2012;9(3):408-15. https://doi.org/10.1007/s12182-012-0225-6.

Mazeel MA. Petroleum fiscal systems and contracts. Hamburg: Diplomica Press; 2010.

McIntosh J. Probabilistic modeling for well-construction performance management. J Pet Technol. 2004. https://doi.org/10.2118/11040036-jpt.

Méjean A, Hope C. Modelling the costs of non-conventional oil: a case study of Canadian bitumen. Energy Policy. 2008;36(11):4205-16. https://doi.org/10.1016/j.enpol.2008.07.023.

Méjean A, Hope C. Supplying synthetic crude oil from Canadian oil sands: a comparative study of the costs and $\mathrm{CO}_{2}$ emissions of mining and in situ recovery. Energy Policy. 2013;60:27-40. https://doi.org/10.1016/j.enpol.2013.05.003.

Mohamed S, McCowan AK. Modelling project investment decisions under uncertainty using possibility theory. Int $\mathrm{J}$ Proj Manag. 2001;19(4):231-41. https://doi.org/10.1016/S0263-7863(99)00077-0.

Montes GM, Martin EP, Bayo JA, Garcia JO. The applicability of computer simulation using Monte Carlo techniques in windfarm profitability analysis. Renew Sustain Energy Rev. 2011;15(9):4746-55. https://doi.org/10.1016/j.rser.2011.07.078.

Osterloh WT, Mims DS, Meddaugh WS. Probabilistic forecasting and model validation for the first-eocene large-scale pilot Steamflood, Partitioned Zone, Saudi Arabia and Kuwait. SPE Reserv Eval Eng. 2013. https://doi.org/10.2118/150580-pa.

Richardson J, Yu W. Calculation of estimated ultimate recovery and recovery factors of shale-gas wells using a probabilistic model of original gas in place. SPE Reserv Eval Eng. 2018. https://doi. org/10.2118/189461-pa.

Rivera N, et al. Static and dynamic uncertainty management for probabilistic production forecast in Chuchupa Field, Colombia. SPE Reserv Eval Eng. 2007. https://doi.org/10.2118/100526-pa.

Schwartz ES. The stochastic behavior of commodity prices: implications for valuation and hedging. J Finance. 1997;52(3):923-73. https://doi.org/10.1111/j.1540-6261.1997.tb02721.x.

SQW. Economic study for ocean energy development in Ireland. 2010. http://www.seai.ie/Renewables/Ocean_Energy/Ocean_Energy_ Information_Research/Ocean_Energy_Publications/SQW_Eco nomics_Study.pdf.

Suslick SB, Schiozer DJ. Risk analysis applied to petroleum exploration and production: an overview. J Pet Sci Eng. 2004;44(1-2):1-9. https://doi.org/10.1016/j.petrol.2004.02.001.

van der Poel R, Jansen JD. Probabilistic analysis of the value of a smart well for sequential production of a stacked reservoir. J Pet Sci Eng. 2004;44(1-2):155-72. https://doi.org/10.1016/j.petrol. 2004.02.012.

Wang Z, Li L. Valuation of the flexibility in decision-making for revamping installations - a case from fertilizer plants. Pet Sci. 2010;7(3):428-34. https://doi.org/10.1007/s12182-010-0089-6.

Wang Q, Zhang BS. Risk analysis of overseas oil and gas exploration and development-taking the Central Asia as an example. J Tech Econ Manag. 2012;01:23-36. https://doi.org/10.3969/j.issn. 1004-292X.2012.01.005 (in Chinese).

Wang Z, Zhao L, Liu M. Impacts of PSC elements on contracts economics under oil price uncertainty. In: International conference on E-business and E-government, Guangzhou China. 2010.

Wang DJ, Li XS, Liu MM, Wang Z. A simulation analysis of international petroleum contracts based on the stochastic process of oil price. Acta Pet Sin. 2012;33(3):513-8. https://doi.org/10. 7623/syxb201203026 (in Chinese).

Weijermars R, Sorek N, Sen D, Ayers WB. Eagle Ford Shale play economics: U.S. versus Mexico. J Nat Gas Sci Eng. 2017;38:345-72. https://doi.org/10.1016/j.jngse.2016.12.009.

Welkenhuysen K, Rupert J, Compernolle T, Ramirez A, Swennen R, Piessens K. Considering economic and geological uncertainty in the simulation of realistic investment decisions for $\mathrm{CO}_{2}$-EOR projects in the North Sea. Appl Energy. 2017;185:745-61. https://doi.org/10.1016/j.apenergy.2016.10.105.

Yan W, Cheng ZY, Li HD. Risk statistics and decision analysis. Beijing: Economy \& Management Publishing House; 1999 (in Chinese).

Zhang BS, Wang Q, Wang YJ. Model of risk-benefit co-analysis of oversea oil and gas projects and its applications. Syst Eng Theory Pract. 2012;32(02):246-56. https://doi.org/10.3969/j. issn.1000-6788.2012.02.003 (in Chinese).

Zhao L, Feng LY. Establishment and application of evaluation and investment timing model for undeveloped oilfields. J China Univ 
Pet. 2009;33(6):161-6. https://doi.org/10.3321/j.issn:1673-5005. 2009.06.033 (in Chinese).

Zhu L, Zhang Z, Fan Y. Overseas oil investment projects under uncertainty: how to make informed decisions? J Policy Model.
2015;37(5):742-62. https://doi.org/10.1016/j.jpolmod.2015.08. 001 . 